\title{
Apical microleakage of different root canal sealers after use of maleic acid and EDTA as final irrigants
}

Özgür illke ULUSOY(a)

Yelda NAYIR(a)

Kezban ÇELIK(b)

Sis Darendeliler YAMAN(a)

(a) Department of Endodontics, Faculty of Dentistry, Gazi University, Ankara, Turkey.

(b) Department of Endodontics, Faculty of Dentistry, Selçuk University, Konya, Turkey.

Declaration of Interests: The authors certify that they have no commercial or associative interest that represents a conflict of interest in connection with the manuscript.

Corresponding Author:

Özgür Illke Ulusoy

E-mail: ilkeatasoy@yahoo.com

DOI: 10.1590/1807-3107BOR-2014.vol28.0048

Submitted: Nov 29, 2013

Accepted for publication: Jun 09, 2014

Last revision: Aug 18, 2014

\begin{abstract}
This study aimed to compare the effects of ethylenediaminetetraacetic acid (EDTA) and maleic acid (MA) on the sealing ability of various root canal sealers. Eighty root canals were instrumented and irrigated with either EDTA or MA. They were divided into eight experimental groups and obturated as follows: Group 1: MA + Hybrid Root SEAL/ gutta-percha. Group 2: EDTA + Hybrid Root SEAL/gutta-percha. Group 3: MA + iRoot SP/gutta-percha. Group 4: EDTA + iRoot SP/gutta-percha. Group 5: MA + EndoREZ/EndoREZ points. Group 6: EDTA + EndoREZ/ EndoREZ points. Group 7: MA + AH Plus/gutta-percha. Group 8: EDTA + $\mathrm{AH}$ Plus/gutta-percha. Another ten roots were used as negative and positive controls. The microleakage of each sample was measured at 2-min intervals for $8 \mathrm{~min}$ using the fluid filtration method. Data were statistically analyzed with one-way ANOVA, post-hoc Tukey, and paired-samples $\mathrm{t}$ tests. The minimum microleakage values were obtained from the teeth obturated with AH Plus and EndoREZ selaers ( $p<0.001)$. The samples with Hybrid Root SEAL showed the maximum leakage $(p<0.001)$. There were significant differences between the groups irrigated with MA or EDTA in terms of microleakage $(p<0.05)$. Use of MA resulted in higher microleakage values compared with those using EDTA. The type of final irrigation solution seems to influence the postobturation apical seal. Use of AH Plus and EndoREZ sealers showed better sealing ability compared with IRoot SP and Hybrid Root SEAL.
\end{abstract}

Keywords: Edetic Acid; Endodontics; Dental Leakage.

\section{Introduction}

It has been suggested that complete removal of the smear layer from root canal walls enhances sealer penetration into the dentinal tubules. ${ }^{1}$ Therefore, irrigation procedures are thought to influence the adhesion of sealers to root dentin..$^{2,3}$ Any failure in adhesion may result in microleakage between the root canal materials and the root dentin.

Ethylenediaminetetraacetic acid (EDTA) is a commonly used irrigation material that removes the smear layer from root dentin walls. However, it was found ineffective in eliminating the smear layer from the apical third of the root canals. ${ }^{4}$ In recent years, maleic acid (MA) has been shown to be more effective than EDTA in removing the smear layer, ${ }^{5}$ which may contribute to better adhesion of root canal sealers to root dentin, thus decreasing microleakage. 
Hybrid Root SEAL is a dual-cure, self-etching resin cement containing 4-methacryloyloxyethyl trimellitate anhydride (4-META). The major mechanism of its bonding properties is formation of hybridized dentin. ${ }^{6}$ The manufacturer suggests that Hybrid Root SEAL be used with either Resilon or gutta-percha core material.

IRoot SP is an aluminum-free, hydrophilic, calcium silicate-based root canal sealer that is available in premixed, ready-to-use injectable form. The material needs water to set and harden. The manufacturer claims that iRoot SP shows improved sealing ability with or without use of any core material.

EndoREZ is a first-generation, nonetching root canal obturation system consisting of resin-coated gutta-percha cones and urethane dimethacrylatebased sealer. The system contains nonacidic, hydrophilic resin monomers to enhance sealer penetration into dentinal tubules after smear layer removal. ${ }^{7}$

AH Plus is a widely used epoxy resin-based root canal sealer that has been shown to have higher bond strength to root dentin and lower volumetric shrinkage during polymerization compared with methacrylate resin-based selaers. ${ }^{8,9}$

Many studies have evaluated the sealing performance of different sealers. ${ }^{10,11,12}$ However, there are no data about the effect of MA on their sealing ability. Thus, the aim of this study was twofold: first, to compare the effects of MA and EDTA on the sealing ability of various sealers; second, to compare the apical sealing performance of Hybrid Root SEAL, iRoot SP, EndoREZ, and AH Plus using the fluid filtration method.

\section{Methodology}

Ninety freshly extracted, single-rooted mandibular premolars with similar dimensions were selected. All teeth were free of caries, cracks, and immature apices, and they were stored in distilled water until use. Then they were decoronated at the cementoenamel junction with a high-speed bur and water spray, leaving a standard root length of $13 \mathrm{~mm}$. Following access cavity preparation, the working lengths of 85 roots were determined by subtracting $0.5 \mathrm{~mm}$ from the apical foramen. Then the root canals were instrumented with ProTaper rotary files (Dentsply-Maillefer, Ballaigues, Switzerland) to a master apical size of 30 (F3). During instrumentation, the root canals were irrigated with $2 \mathrm{~mL}$ of $2.5 \% \mathrm{NaOCl}$ solution (Rehber Chemistry, Istanbul, Turkey) using a 30-gauge needle.

Eighty roots were divided into eight experimental groups containing 10 roots each. The roots in the groups 1, 3, 5 and 7 received a final irrigation with 2 mL of 7\% MA (Ankara University Faculty of Science, Ankara, Turkey) for $2 \mathrm{~min}$. The roots in groups 2, 4, 6 , and 8 received a final irrigation with $2 \mathrm{~mL}$ of $18 \%$ EDTA (Ultradent, South Jordan, USA) for $2 \mathrm{~min}$. All the root canals were then washed with $2 \mathrm{~mL}$ distilled water and dried with paper points. The root canals were obturated as follows:

Group 1 (MA + Hybrid Root SEAL/gutta-percha): The roots were obturated with Hybrid Root SEAL (Sun Medical, Tokyo, Japan) and guttapercha points using the cold lateral condensation (CLC) technique. According to the manufacturer's instructions, three drops of liquid and 1 scoop of powder were mixed with a spatula and placed in the root canal using a paper point. A \#30/ 0.04 tapered master gutta-percha point was lightly coated with the sealer and placed in the root canal to the working length. Lateral compaction was performed using fine accessory guttapercha points and appropriate finger spreaders. The excess material was removed with a heated instrument and condensed vertically. The coronal surfaces of the root canal fillings were lightcured for $20 \mathrm{~s}$.

Group 2 (EDTA + Hybrid Root SEAL/gutta-percha): The roots were obturated with Hybrid Root SEAL and \#30/0.04 tapered gutta-percha points using CLC following the same protocol as in group 1 . The coronal surfaces were light-cured for $20 \mathrm{~s}$.

Group 3 (MA + iRoot SP sealer/gutta-percha): The roots were filled with iRoot SP (Innovative BioCreamix Inc, Vancouver, Canada) which was premixed in an injectable form and \#30/0.04 tapered gutta percha cones using CLC as described above.

Group 4 (EDTA + iRoot SP sealer/gutta-percha): The roots were filled as in group 3.

Group 5 (MA + EndoREZ sealer/EndoREZ points): The roots were obturated with EndoREZ sealer 
(Ultradent, South Jordan, USA) and \#30/0.04 tapered EndoREZ points using CLC in the same manner as group 1. EndoREZ sealer was prepared according to the manufacturer's instructions. The roots were light-cured from the coronal side for $20 \mathrm{sec}$.

Group 6 (EDTA + EndoREZ sealer/EndoREZ points): The roots were filled with EndoREZ sealer and \#30/0.04 tapered EndoREZ points as in group 5 and light-cured for $20 \mathrm{sec}$.

Group 7 (MA + AH Plus sealer/gutta-percha): The roots were obturated with AH Plus sealer (Dentsply, Konstanz, Germany) and \#30/0.04 tapered guttapercha points using CLC.

Group 8 (EDTA + AH Plus sealer/gutta-percha): The roots were obturated as in group 7 .

Five instrumented roots, not obturated, served as positive controls. Another five roots, which were nonprepared and unfilled, were completely covered with two layers of nail varnish, which served as negative controls.

Access cavities of the obturated roots were sealed with temporary filling material (3M ESPE, Seefeld, Germany). The specimens were stored at $37^{\circ} \mathrm{C}$ and $100 \%$ humidity for 1 week to allow the sealers to set completely.

\section{Fluid Filtration Test}

A fluid filtration study design previously reported by Pashley and Depew ${ }^{13}$ was used. After we removed the temporary fillings, the apical 3 $\mathrm{mm}$ of the roots was inserted and attached to a silicone tube having a 3-mm internal diameter and cyanoacrylate adhesive. The tube was connected to a fluid filtration apparatus as described by Derkson et al. ${ }^{14}$ and modified by Wu et al. ${ }^{15}$ for endodontic studies. The pressure reservoir was connected to a $25-\mu \mathrm{L}$ micropipette (Fisher Scientific, Philadelphia, USA) with polyethylene tubing (Fisher Scientific, Pittsburgh, USA).

Then the micropipette was connected to a microsyringe (Gilmont Instruments Inc., New York, USA) and the silicone tube with the attached root. The tubing, pipette, and syringe were filled with distilled water under a pressure of $202 \mathrm{kPA}$ using $\mathrm{O}_{2}$ gas. The sealing ability of the samples were measured by following the progress of the tiny air bubble traveling within the micropipette. Fluid movements were measured and recorded at 2-min intervals for $8 \mathrm{~min}$ and averaged. The values were expressed as $\mathrm{L} / \mathrm{min} / \mathrm{cm} \mathrm{H}_{2} \mathrm{O}$. The data were statistically analyzed by using one-way analysis of variance (ANOVA), post-hoc Tukey, and paired-samples $t$ tests. The statistical analysis was performed with SPSS 15.0 (SPSS Inc., Chicago, USA) for Windows. A p value of $<0.05$ was considered significant.

\section{Results}

Positive controls showed rapid air bubble movement as expected. The varnish-coated negative controls exhibited no measurable bubble movement. The mean, standard error, minimum, and maximum values of microleakage for the experimental groups are shown in Tables 1 and 2 . There were statistically significant differences between the groups obturated with different sealers $(\mathrm{p}<$ 0.001). The minimum microleakage values were obtained from the teeth obturated with AH Plus sealer/gutta-percha points and EndoREZ selaer/ EndoREZ points. The teeth obturated with Hybrid Root SEAL/gutta-percha points showed the maximum leakage $(p<0.001)$. There were significant differences between the groups irrigated with MA or EDTA in terms of microleakage ( $<<0.05)$. Use of MA resulted in higher microleakage values compared with those of EDTA.

Table 1. Means and standard deviations of the microleakage values

\begin{tabular}{|c|c|c|c|}
\hline \multirow{2}{*}{ Sealers } & MA & EDTA & \multirow{2}{*}{$p^{\pi}$} \\
\hline & Mean \pm SD & Mean \pm SD & \\
\hline $\begin{array}{l}\text { Hybrid Root } \\
\text { SEAL }\end{array}$ & $\begin{array}{c}0.000853 \\
(0.000122)^{a}\end{array}$ & $\begin{array}{c}0.000678 \\
(0.000164)^{a}\end{array}$ & 0.037 \\
\hline ¡Root SP & $\begin{array}{c}0.000591 \\
(0.000190)^{b}\end{array}$ & $\begin{array}{c}0.000489 \\
(0.000254)^{a, b}\end{array}$ & 0.177 \\
\hline EndoREZ & $\begin{array}{c}0.000401 \\
(0.000106)^{c}\end{array}$ & $\begin{array}{c}0.000313 \\
(0.000195)^{b}\end{array}$ & 0.047 \\
\hline AH Plus & $\begin{array}{c}0.000367 \\
(0.00046)^{c}\end{array}$ & $\begin{array}{c}0.000346 \\
(0.000082)^{b}\end{array}$ & 0.435 \\
\hline$p^{*}$ & $<0.001$ & $<0.001$ & \\
\hline $\begin{array}{l}\text { Different letter } \\
\text { * One-way Al } \\
\text { "Paired-samp } \\
\text { SD: Standard } \\
\text { MA: Maleic a } \\
\text { EDTA: Ethylen }\end{array}$ & $\begin{array}{l}\text { cate significant } \\
\text { st } \\
\text { tion }\end{array}$ & ences between th & groups \\
\hline
\end{tabular}


Table 2. Mean, standard error, minimum, and maximum microleakage values of the groups

\begin{tabular}{|c|c|c|c|c|c|}
\hline Groups & $\mathrm{N}$ & Mean & Standard error & Minimum & Maximum \\
\hline $\begin{array}{l}\text { Group 1: } \\
\text { Maleic acid + brid Root SEAL/Gutta-percha }\end{array}$ & 10 & 0.000853 & 0.000039 & 0.000715 & 0.001093 \\
\hline $\begin{array}{l}\text { Group 2: } \\
\text { EDTA + Hybrid Root SEAL/Gutta-percha }\end{array}$ & 10 & 0.000678 & 0.000052 & 0.000338 & 0.000825 \\
\hline $\begin{array}{l}\text { Group 3: } \\
\text { Maleic acid + iRoot Sp sealer/Gutta- } \\
\text { percha }\end{array}$ & 10 & 0.000591 & 0.000060 & 0.000278 & 0.000944 \\
\hline $\begin{array}{l}\text { Group 4: } \\
\text { EDTA + iRoot Sp sealer/Gutta-percha }\end{array}$ & 10 & 0.000489 & 0.000080 & 0.000040 & 0.000815 \\
\hline $\begin{array}{l}\text { Group 5: } \\
\text { Maleic acid + EndoREZsealer/EndoREZ } \\
\text { points }\end{array}$ & 10 & 0.000401 & 0.000034 & 0.000229 & 0.000527 \\
\hline $\begin{array}{l}\text { Group 6: } \\
\text { EDTA + EndoREZsealer/EndoREZ points }\end{array}$ & 10 & 0.000313 & 0.000062 & 0.000010 & 0.000596 \\
\hline $\begin{array}{l}\text { Group 7: } \\
\text { Maleic acid + us sealer/Gutta-percha }\end{array}$ & 10 & 0.000367 & 0.000015 & 0.000298 & 0.000467 \\
\hline $\begin{array}{l}\text { Group 8: } \\
\text { EDTA+ } \\
\text { AH Plus sealer/Gutta-percha }\end{array}$ & 10 & 0.000346 & 0.000026 & 0.000248 & 0.000477 \\
\hline
\end{tabular}

\section{Discussion}

It is generally accepted that complete removal of the smear layer from root canal walls induces penetration of the root canal sealers into the root dentin, thereby decreasing microleakage. ${ }^{1,16}$ In a recent study, MA was found to be superior to EDTA in removing the smear layer from the apical third of root canals. ${ }^{5}$ Ballal et al. ${ }^{17}$ also concluded that postobturation apical seal was improved after final irrigation with $7 \%$ MA compared with 17\% EDTA, using the dye leakage method. However, the current study revealed that the irrigation protocol using MA resulted in more microleakage than with EDTA. This contradiction might be attributed to the diversity of microleakage measurement methods and the type of sealers used. In addition, successful removal of the smear layer may not always result in an improved apical seal. ${ }^{18}$ There exists literature suggesting that there is no correlation between smear layer, leakage, and bonding strength of the sealers. . $^{1920,21}$

Several methods have been used to evaluate the sealing ability of root canal filling materials. ${ }^{12,17,22}$ Linear dye microleakage is a commonly used technique to assess leakage in root canals. However, it has some limitations such as the need for sample sectioning and possible prevention of dye penetration due to the air inside the root canal. ${ }^{23,24}$ The fluid filtration method used in the current study has been reported to be more reliable and advantageous than that of dye penetration, as it provides quantitative and volumetric data without destroying the samples. ${ }^{11}$

In the present study, the minimum leakage was observed in the samples filled with EndoREZ sealer/ EndoREZ points and AH Plus sealer/gutta-percha points. The highest microleakage results were obtained from the roots filled with Hybrid Root SEAL/gutta percha. Similar to our results, another methacrylate resin-based obturation system (Resilon/Epiphany), including its special core and sealer, showed similar microleakage values with AH Plus and gutta-percha. ${ }^{25}$ The lower microleakage results obtained from the EndoREZ system may be related to the use of special gutta-percha cones coated with resin, which allowed a more successful adaptation between the core material and sealer. On the contrary, use of traditional gutta-percha cones in the Hybrid Root SEAL group may have prevented the adhesive bonding between the core material and sealer. Similarly, Onay et al. ${ }^{26}$ reported greater microleakage with EDTA+Hybrid Root SEAL/gutta-percha than with EDTA+AH26/gutta-percha by using a computerized fluid filtration method.

It has been suggested that the systems-aiming "monoblock" improves the fracture resistance of roots by providing a hermetic seal inside the root canal. ${ }^{27}$ The studies comparing push-out bond strength and 
fracture resistance of EndoREZ and Hybrid Root SEAL indicated the superiority of Hybrid Root SEAL. ${ }^{28,29}$ However, the high microleakage values obtained from Hybrid Root SEAL in the present study suggest its relative inability to form monoblock.

The apical region of human teeth represents irregular and variable structure, which may influence the dentin-bonding ability of obturation materials, including adhesives. ${ }^{30}$ Hybrid Root SEAL is a selfadhesive, methacrylate resin-based sealer, and the success of bonding depends largely on the successful removal of the smear layer in the apical third. ${ }^{28}$ In the current study, the use of MA and EDTA as final irrigants might have been insufficient to achieve complete smear layer removal. Although EDTA is a widely used irrigant for eliminating the smear layer, use of stronger acid solutions such as phosphoric acid might be more appropriate to improve

\section{References}

1. Kokkas AB, Boutsioukis ACh, Vassiliadis LP, Stavrianos CK. The influence of the smear layer on dentinal tubule penetration depth by three different root canal sealer: an in vitro study. J Endod. 2004 Feb;30(2):100-2.

2. De-Deus G, Namen F, Galan Júnior J, Zehnder M. Soft chelating irrigation protocol optimizes bonding quality of Resilon/ Epiphany root fillings. J Endod. 2008 Jun;34(6):703-5.

3. Nunes VH, Silva RG, Alfredo E, Sousa-Neto MD, Silva-Sousa YT. Adhesion of Epiphany and AH Plus sealers to human root dentin treated with different solutions. Braz Dent J. 2008;19(1):46-50.

4. Khedmat S, Shokouhinejad N. Comparison of the efficacy of three chelating agents in smear layer removal. J Endod. 2008 May;34(5):599-602.

5. Ballal NV, Kandian S, Mala K, Bhat KS, Acharya S. Comparison of the efficacy of maleic acid and ethylenediaminetetraacetic acid in smear layer removal from instrumented human root canal: a scanning electron microscopic study. J Endod. 2009 Nov;35(11):1573-76.

6. Nakabayashi N, Takarada K. Effect of HEMA on bonding to dentin. Dent Mater. 1992 Mar;8(2):125-30.

7. Tay FR, Loushine RJ, Monticelli F, Weller RN, Breschi L, Ferrari $\mathrm{M}$, et al. Effectiveness of resin-coated gutta-percha cones and a dual-cured, hydrophilic methacrylate resin-based sealer in obturating root canals. J Endod. 2005 Sep;31(9):659-64.

8. De-Deus G, Di Giorgi K, Fidel S, Fidel RA, Paciornik S. Pushout bond strength of Resilon/Epiphany and Resilon/Epiphany self-etch to root dentin. J Endod. 2009 Jul;35(7):1048-50. the penetration of methacrylate resin-based sealars into the dentinal tubules. Further studies using different irrigation solutions to decrease the microleakage of methacrylate and bioceramic-based sealers might be helpful in clarifying this situation.

\section{Conclusions}

1-The postobturation apical seal seems to have been influenced by the final irrigation solution.

2-Use of AH Plus and EndoREZ selaers instead of iRootSP and Hybrid Root SEAL resulted in an improved apical seal.

\section{Acknowledgement}

The authors would like to thank Research Assisstant Rabia Albayrak (Ankara University, Faculty of Agriculture, Department of Animal Science Biometry and Genetics) for her assistance in the statistical analysis.

9. Gesi A, Raffaelli O, Goracci C, Pashley DH, Tay FR, Ferrari M. Interfacial strength of Resilon and gutta-percha to intraradicular dentin. J Endod. 2005 Nov;31(11):809-13.

10. Karapinar-Kazandağ M, Tanalp J, Bayrak OF, Sunay $H$, Bayirli G. Microleakage of various root filling systems by glucose filtration analysis. Oral Surg Oral Med Oral Pathol Oral Radiol Endod. 2010 Jun;109(6):e96-102.

11. Orucoglu H, Sengün A, Yilmaz N. Apical leakage of resin based root canal sealers with a new computerized fluid filtration meter. J Endod. 2005 Dec;31(12):886-90.

12. Pommel L, About I, Pashley D, Camps J. Apical leakage of four endodontic sealers. J Endod. 2003 Mar;29(3):208-10.

13. Pashley DH, Depew DD. Effects of the smear layer, copalite, and oxalate on microleakage. Oper Dent. 1986 Summer;11(3):95-102.

14. Derkson GD, Pashley DH, Derkson ME. Microleakage measurement of selected restorative materials: a new in vitro method. J Prosthet Dent. 1986 Oct;56(4):435-40.

15. Wu MK, De Gee AJ, Wesselink PR, Moorer WR. Fluid transport and bacterial penetration along root canal fillings. Int Endod J. 1993 Jul;26(4):203-8.

16. Cobankara FK, Adanr N, Belli S. Evaluation of the influence of smear layer on the apical and coronal sealing ability of two sealers. J Endod. 2004 Jun;30(6):406-9.

17. Ballal NV, Kundabala M, Bhat KS. A comparative evaluation of postobturation apical seal following intracanal irrigation with maleic acid and EDTA: a dye leakage under vacuum study. Oral Surg Oral Med Oral Pathol Oral Radiol Endod. 2010 Mar;109(3):e126-30. 
18. Tzanetakis GN, Kakavetsos VD, Kontakiotis EG. Impact of smear layer on sealing property of root canal obturation using 3 different techniques and sealers. Part I. Oral Surg Oral Med Oral Pathol Oral Radiol Endod. 2010 Feb;109(2):e145-53.

19. Ghoddusi J, Dibaji F, Marandi S. Correlation between sealer penetration and microleakage following the use of MTAD as a final irrigant. Aust Endod J. 2010 Dec;36(3):109-13.

20. Saleh IM, Ruyter IE, Haapasalo MP, Orstavik D. Adhesion of endodontic sealers: scanning electron microscopy and energy dispersive spectroscopy. J Endod. 2003 Sep;29(9):595-601.

21. Saleh IM, Ruyter IE, Haapasalo M, Ørstavik D. The effects of dentine pretreatment on the adhesion of root-canal sealers. Int Endod J. 2002 Oct;35(10):859-66.

22. Saleh IM, Ruyter IE, Haapasalo M, Ørstavik D. Bacterial penetration along different root canal filling materials in the presence or absence of smear layer. Int Endod J. 2008 Jan;41(1):32-40.

23. Camps J, Pashley D. Reliability of the dye penetration studies. J Endod. 2003 Sep;29(9):592-4.

24. Spangberg LS, Acierno TG, Yongbum Cha B. Influence of entrapped air on the accuracy of leakage studies using dye penetration methods. J Endod. 1989 Nov;15(11):548-51.
25. Shokouhinejad N, Sharifian MR, Aligholi M, Assadian H, Tabor RK, Nekoofar MH. The sealing ability of resilon and gutta-percha following different smear layer removal methods: an ex vivo study. Oral Surg Oral Med Oral Pathol Oral Radiol Endod. 2010 Jul;110(1):e45-9.

26. Onay EO, Orucoglu H, Kiremitci A, Korkmaz Y, Berk G. Effect of Er, Cr:YSGG laser irradiation on the apical sealing ability of AH Plus/gutta-percha and Hybrid Root Seal/Resilon combinations. Oral Surg Oral Med Oral Pathol Oral Radiol Endod. 2010 Nov;110(5):657-64.

27. Hammad M, Qualtrough A, Silikas N. Effect of new obturating materials on vertical root fracture resistance of endodontically treated teeth. J Endod. 2007 Jun;33(6):732-36.

28. Babb BR, Loushine RJ, Bryan TE, Ames JM, Causey MS, Kim $\mathrm{J}$, et al. Bonding of self-adhesive (self-etching) root canal sealers to radicular dentin. J Endod. 2009 Apr;35(4):578-82.

29. Ulusoy OI, Nayır Y, Darendeliler-Yaman S. Effect of different root canal sealers on fracture strength of simulated immature roots. Oral Surg Oral Med Oral Pathol Oral Radiol Endod. 2011 Oct;112(4):544-7.

30. Mjör IA, Smith MR, Ferrari M, Mannocci F. The structure of dentine in the apical region of human teeth. Int Endod J. 2001 Jul;34(5):346-53. 